Jurnal Pemberdayaan: Publikasi Hasil Pengabdian kepada Masyarakat

Vol. 2, No. 2, Agustus2018, Hal. 211-220

ISSN: 2088 4559; e-ISSN: XXXX-XXXX

DOI:

\title{
PELATIHAN PENGELOLAAN MATERI PEMBELAJARAN DENGAN E-LEARNING BAGI SEKOLAH MUHAMMADIYAH DI KECAMATAN MOYUDAN, KABUPATEN SLEMAN
}

\author{
Sri Winiarti ${ }^{1}$, Nur Rochmah Dyah Puji Astuti ${ }^{2}$, Herman Yuliansyah ${ }^{3}$ \\ Universitas Ahmad Dahlan, Yogyakarta ${ }^{1,2,3}$ \\ Email: herman.yuliansyah@tif.uad.ac.id ${ }^{3}$
}

\begin{abstract}
ABSTRAK
Sekolah-sekolah di wilayah Kecamatan Moyudan, Kabupaten Sleman, Daerah Istimewa Yogyakarta belum memaksimalkan penggunaan teknologi informasi untuk mendukung kegiatan belajar dan mengajar. Maka diperlukan pendampingan dalam pengabdian masyarakat berupa pelatihan pengelolaan materi pembelajaran dengan e-learning. Kegiatan ini bertujuan (1) memberikan tambahan pengetahuan dan keterampilan pemanfaatan teknologi informasi kepada guru/staf sekolah-sekolah Muhammadiyah di Kelurahan Sumber Agung, Kecamatan Moyudan, Kabupaten Sleman, (2) melatih para guru agar dapat memanfaatkan teknologi informasi pada lingkungan sekolah baik untuk meningkatkan proses pembelajaran, dan (3) memberikan media alternatif pembelajaran melalui e-learning. Meningkatkan keahlian dalam membuat materi mata pelajaran, soal dan latihan secara bebas kepada siswa dan mudah diakses. Metode pelaksanaan pelatihan adalah pemberian modul bagi peserta, tutorial/pendampingan, pelatihan/workshop dan evaluasi proses. Hasil dan dampak dari pelatihan ini adalah adanya perbaikan dalam pemahaman penggunaan teknologi informasi, hal ini terlihat dari kuisioner hasil pelatihan yaitu sebesar $74 \%$ yang berarti setuju, baik atau suka.
\end{abstract}

Kata kunci: Pelatihan, Teknologi Informasi, Elearning, Media Pembelajaran, Sekolah Muhammadiyah.

\begin{abstract}
The schools in Mayodan sub-district have not used information technology with maximum to support learning and education activity. They need assistance in community service to train them to organize learning media using eLearning. The methods of implementing the training are tutorial or assistance, giving a module to participants, workshop and evaluation process. The impact of this training is improvement knowledge in information technology uses. This impact can show from training result. The result showed 74\% participants agree and like with this training results.
\end{abstract}

Keywords : training, information technology, eLearning, learning media, school of muhammadiyah 


\section{PENDAHULUAN}

Sekolah-sekolah Muhammadiyah yang berada di wilayah Kecamatan Moyudan, Kabupaten Sleman, DIY belum memaksimalkan penggunaan teknologi informasi di lingkungan sekolah. Hal ini disebabkan oleh dua faktor, pertama minimnya pengetahuan guru dan staf tentang teknologi informasi yang meliputi internet dan keterbatasan sumber daya manusia. Faktor kedua adalah minimnya sarana dan prasarana yang tersedia di sekolah. Tidak semua Sekolah Dasar (SD) Muhammadiyah di Kecamatan Moyudan memiliki fasilitas komputer yang memadai.

Berdasarkan permasalahan tersebut, maka perlu dilakukan pendampingan pengelolaan media pembelajaran berupa pelatihan kepada guru dan staf di sekolah Muhammadiyah Kecamatan Moyudan. Sasaran yang dituju dalam pelatihan ini adalah para stakeholder (guru dan staf) sekolah-sekolah Muhammadiyah di wilayah Kecamatan Moyudan, Kabupaten Sleman, Ranting Sendang Arum. Adapun target peserta adalah 25 dengan berkerjasama dengan PCM Ranting Sumber Agung. Pelaksanaan pelatihan akan dilaksanakan di Laboratorium Komputer milik SMK Muhammadiyah Moyudan.

Adapun tujuan dari kegiatan ini adalah memberikan tambahan pengetahuan dan keterampilan pemanfaatan teknologi informasi kepada guru/staf sekolah-sekolah Muhammadiyah di Kelurahan Sumber Agung, Kecamatan Moyudan, Kabupaten Sleman. Melatih para guru agar dapat memanfaatkan teknologi informasi pada lingkungan sekolah baik untuk meningkatkan proses pembelajaran maupun memberikan media alternatif pembelajaran melalui e-learning. Meningkatkan keahlian dalam membuat materi mata pelajaran, soal, dan latihan secara bebas kepada siswa dan mudah diakses.

Pelatihan pengelolaan media pembelajaran ini dilakukan dengan memanfaatkan $e$ learning karena e-learning merupakan usaha untuk membuat sebuah transformasi proses belajar mengajar di sekolah dalam bentuk digital yang dijembatani oleh teknologi internet (Kuswari, 2011). Adapun e-learning yang dilatihkan adalah Google Classrom dan Moodle. Google adalah aplikasi web yang dapat digunakan secara gratis untuk sekolah, non-profit, atau siapapun dengan dengan akun Google pribadi (Google.com, 2018), sedangkan Moodle adalah sebuah platform pembelajaran yang dirancang untuk para pendidik, administrator dan pembelajar dengan sistem tunggal yang aman dan terintegrasi untuk membuat lingkungan pembelajaran yang bersifat pribadi. Hal yang membedakan antara Google Classrom dan Moodle adalah dengan Google Classrom, sekolah tidak perlu menyiapkan infrastruktur teknologi informasi meski fitur yang ditawarkan lebih sederhana dari Moodle. Sedangkan 
Moodle membutuhkan infrastruktur teknologi informasi yang harus disediakan oleh sekolah dan memiliki fitur yang lebih kompleks dari Google Classroom.

\section{METODE}

\section{Pemberian Materi}

Pemberian materi dilakukan dengan metode tutorial yang dilakukan selama 2 hari yaitu hari Rabu dan Kamis tanggal 21 dan 22 Maret 2018. Kegiatan pemberian materi dibagi dalam beberapa sesi sesuai dengan jumlah materi yang ada di Google Classroom dan Moodle. Persiapan sampai pelatihan dilakukan mulai pukul 09.00 - 15.30 WIB.

\section{Pemberian modul kepada peserta}

Untuk memudahkan dalam penyampaian materi, peserta diberikan modul yang berisi materi yang akan diberikan. Modul dibuat permateri diurutkan menurut proses yang ada di Google Classroom maupun Moodle. Modul dibuat dalam 2 bentuk yaitu hardcopy dan softcopy. Yang dibagikan satu hari sebelum hari pelatihan melalui koordinator kegiatan dari pihak sekolah. Dengan dibuatkan modul peserta lebih mudah dalam menerima dan memahami materi yang diberikan, sehingga kegiatan ini lebih efektif.

\section{Tutorial}

Dalam kegiatan ini peserta diberikan bimbingan tutorial sesuai urutan materi. Hari pertama materi yang diberikan adalah tentang pengelolaan Google Classroom yang terbagi dalam 2 sesi materi yaitu sesi 1 dengan materi pengenalan Google Classroom, pembuatan kelas dan upload materi. Sesi 2 materi pembuatan tugas, kuis dan pengelolaan nilai. Hari ke dua pengelolaan kelas dengan Moodle yang dibagi dalam materi mengatur materi selama satu semester dengan e-learning, membuat soal latihan, melatih sebagai admin sistem $e$ learning, dan sistem penilaian.

\section{Pelatihaan}

Memberikan contoh dan kasus sederhana, setelah itu peserta diberikan kasus dengan menggunakan materi-materi yang peserta ampu di sekolah masing-masing. Dengan demikian, peserta akan lebih paham dalam mengelola kelas dengan google classroom dan memanfaatkan e-learning dengan aplikasi moodle.

\section{Evaluasi}

Melakukan evaluasi hasil pelatihan dengan menggunakan kuisioner tentang peningkatan pemahaman terhadap materi yang telah diberikan. 


\section{HASIL, PEMBAHASAN, DAN DAMPAK}

Gambar aktivitas pelaksanaan persiapan dan proses pelatihan pengelolaan media pembelajaran dengan e-learning tersaji pada Gambar 1:

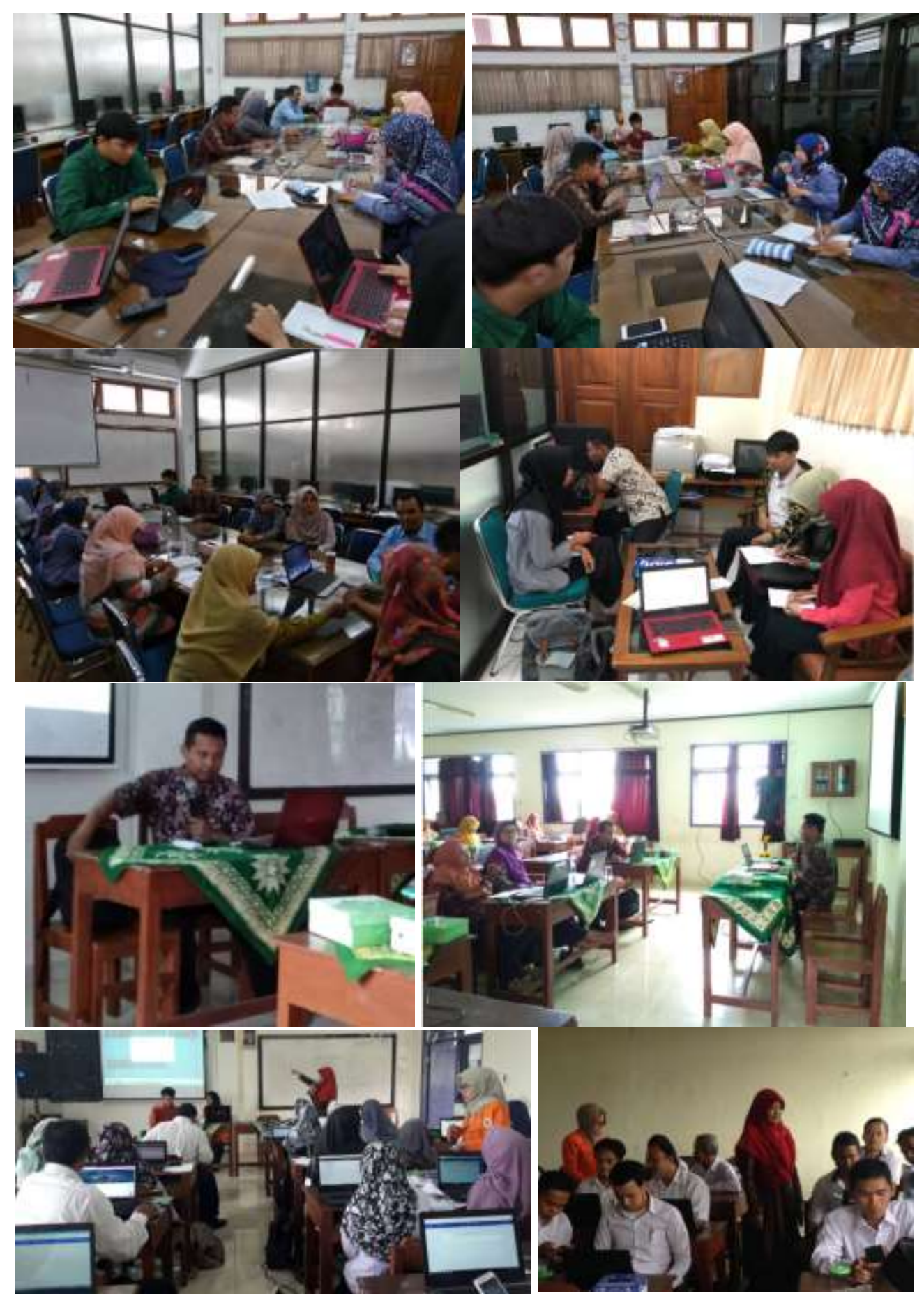



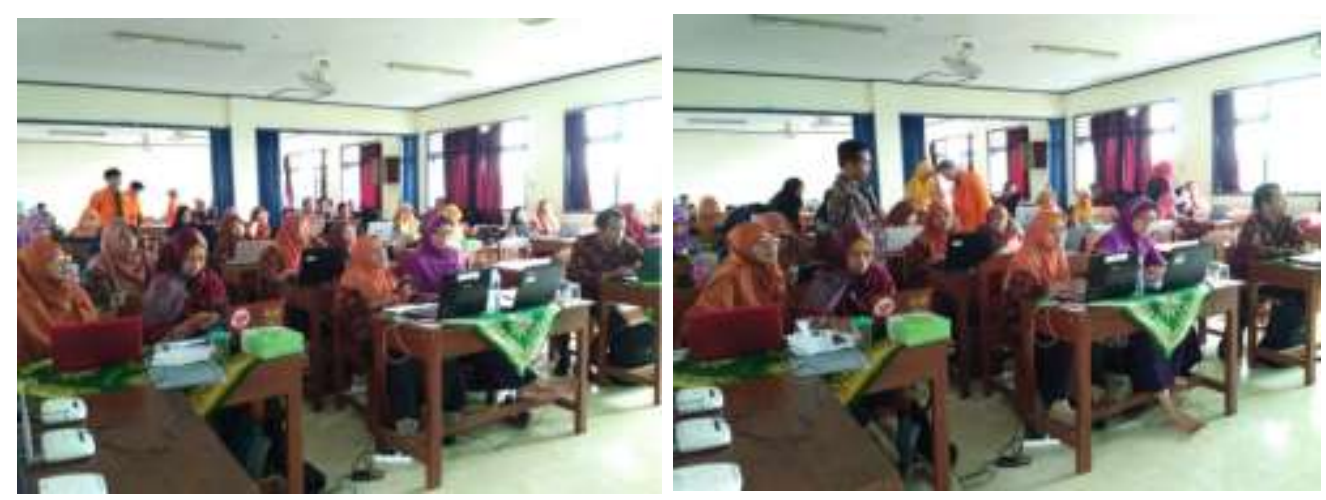

Gambar 1. Aktivitas Pelaksanaan Pelatihan

Dari Gambar 1 terlihat program pelatihan ini dapat terlaksana dengan partisipasi guru dan staf yang cukup tinggi dengan kata lain dapat memperdayakan guru dan staf dalam program-program yang telah direncanakan. Dampak dari kegiatan ini adalah adanya perbaikan dalam pemahaman penggunaan teknologi informasi.

Dengan adanya pelatihan teknologi informasi bagi sekolah Muhammadiyah ini ada peingkatan dalam pemahaman penggunaan sarana teknologi informasi. Peningkatan pemahaman dapat dilihat dari pebandingan kuisioner awal yang telah disebar sebelum adanya penilaian yang berisi tentang pengetahuna peserta atas materi yang akan diberikan. Dan evaluasi akhir setelah dilakukan pelatihan.

\section{Kuisioner Awal}

Kuisioner pada Tabel 1 dilakukan untuk menilai seberapa tingkat pemahaman peserta terhadap materi yang akan diberikan yaitu google classroom dan model.

Tabel 1. kuisioner awal.

\begin{tabular}{|l|l|c|c|}
\hline \multirow{2}{*}{ No } & \multicolumn{1}{|c|}{ Pertanyaan } & \multicolumn{2}{|c|}{ Skala } \\
\cline { 2 - 3 } & Ya & Tidak \\
\hline 1. & Apakah Anda pernah mendengar istilah E-Learning ? & & \\
\hline 2. & Apakah anda pernah menggunakan aplikasi E-Learning ? & \\
\hline 3. & $\begin{array}{l}\text { Apakah anda pernah menggunakan situs web berbasis media pembelajaran online } \\
\text { lainnya? }\end{array}$ & \\
\hline 4. & Apakah anda memiliki email atau gmail ? & & \\
\hline 5. & Pernahkah Anda mendengar tentang aplikasi Google Classroom? & \\
\hline 6. & Pernahkah Anda mengunakan aplikasi Google Classroom ? & \\
\hline 7. & $\begin{array}{l}\text { Bersediakah Anda untuk menggunakan media pembelajaran dengan } \\
\text { menggunakan aplikasi E-Learning untuk alternatif pengembangan materi } \\
\text { pembelajaran? }\end{array}$ & & \\
\hline
\end{tabular}


Terdapat 7 pertanyaan dengan 50 peserta, dengan hasil seperti pada Tabel 2.

Tabel 2. Hasil kuisioner awal.

\begin{tabular}{|c|c|c|c|c|c|c|c|}
\hline Jumlah & P1 & P2 & P3 & P4 & P5 & P6 & P7 \\
\hline ya & 41 & 10 & 19 & 46 & 29 & 4 & 47 \\
\hline tidak & 9 & 40 & 31 & 4 & 21 & 46 & 3 \\
\hline
\end{tabular}

Dari hasil 50 peserta kuisioner awal tersebut dapat disimpulkan bahwa peserta yang sudah mengetahui e-learning sebanyak 41, belum menggunakan e-learning yaitu sebanyak 40 orang, belum pernah menggunakan pembelajaran yang berbasis online sebanyak 31 , belum mempunyai gmail sebanyak 46 orang, sudah mengetahui tentang google classrom sebanyak 21 orang, belum pernah menggunakan google classroom sebanyak 46 orang dan diakhir pertanyaan peserta menyetujui adanya pembelajaran google classrom dan moodle elearning sebanyak 47 orang. Hasil kuisioner dalam grafik terlihat pada Gambar 2.

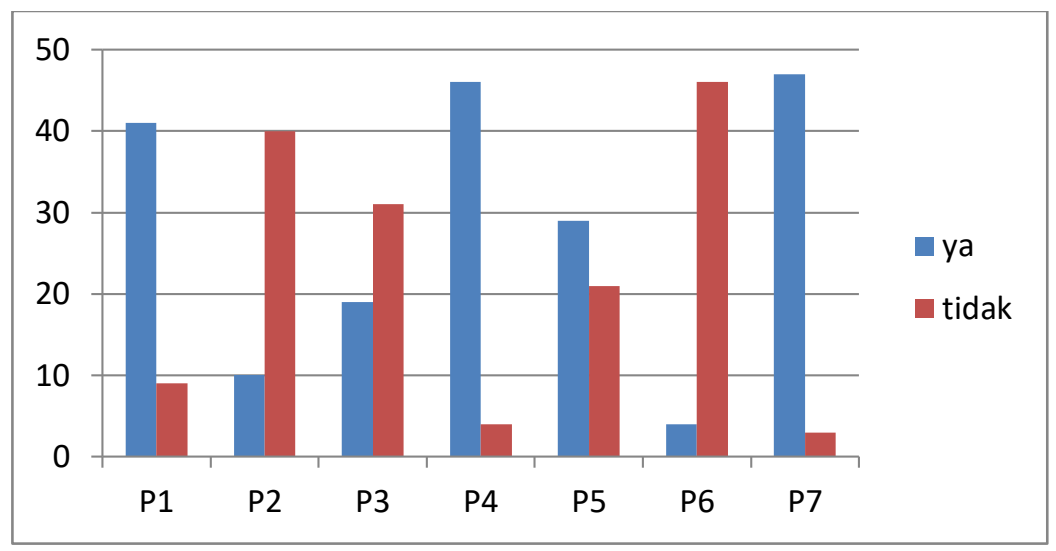

\section{Kuisioner Akhir/Evaluasi Akhir}

Dari hasil kuisioner awal ditetapkan bahwa pelatihan berisi tentang materi google classroom dan moodle e-learning. Setelah dilakukan pelatihan untuk mengetahui peningkatan pemahaman peserta tentang materi tersebut maka dilakukan evaluasi akhir. Evaluasi akhir diberikan dalam bentuk kuisioner seperti Tabel 3 dengan 9 pertanyaan tentang peningkatan pemahaman terhadap materi yang diberikan.

Tabel 3. Daftar Pertanyaan Kuisioner Akhir

\begin{tabular}{|l|l|l|l|l|l|}
\hline \multirow{2}{*}{ No } & \multicolumn{1}{|c|}{ Parameter } & \multicolumn{3}{|c|}{ SkalaPenilaian } \\
\cline { 3 - 5 } & & 1 & 2 & 3 & 4 \\
\hline 1 & Pemahaman mengenai konsep e-learning & & & & \\
\hline 2 & Kemampuan membuat email. & & & \\
\hline 3 & Kemampuan membuat kelas dengan e-learning & & & \\
\hline 4 & Kemampuan mengundang guru pada e-learning & & \\
\hline 5 & $\begin{array}{l}\text { Kemampuan membuat pengumuman dalam kelas yang telah dibuat pada } \\
\text { G classrom. }\end{array}$ & & & \\
\hline 6 & Kemampuan mengupload materi pada e-learning & & & \\
\hline
\end{tabular}




\begin{tabular}{|l|l|l|l|l|l|}
\hline \multirow{2}{*}{ No } & \multicolumn{1}{|c|}{ Parameter } & \multicolumn{3}{|c|}{ SkalaPenilaian } \\
\cline { 3 - 5 } & & 1 & 2 & 3 & 4 \\
\hline 7 & Kemampuan mengelola nilai tugas pada G classroom & & & & \\
\hline 8 & Kemampuan menggunakan salah satu aktivitas tugas pada moodle & & & & \\
\hline 9 & Kemampuan mengoprasikan secara aplikasi google classroom. & & & & \\
\hline
\end{tabular}

Hasil kuisioner menunjukkan adanya peningkatan pemahaman disetiap materi yang diberikan, hasil jawaban dapat dilihat pada tabel 4.

Tabel 4. Kuisioner/evaluasi akhir.

\begin{tabular}{|c|c|c|c|c|c|c|c|c|c|}
\hline Jumlah & P1 & P2 & P3 & P4 & P5 & P6 & P7 & P8 & P9 \\
\hline 1 & 0 & 0 & 0 & 1 & 2 & 0 & 2 & 1 & 1 \\
\hline 2 & 2 & 2 & 2 & 2 & 3 & 6 & 11 & 7 & 11 \\
\hline 3 & 27 & 19 & 24 & 24 & 22 & 20 & 18 & 25 & 21 \\
\hline 4 & 4 & 12 & 7 & 6 & 6 & 7 & 2 & 0 & 0 \\
\hline
\end{tabular}

Dari Tabel 1 dan Tabel 2 hasil dapat disimpulan setelah dilakukan pelatihan maka dapat meningkatkan pengetahuan dan skill karyawan dan guru dalam mengelola kelas dengan google classroom dan moodle e-learning, seperti membuat contens/materi untuk disajikan/diunggah di e-learning, membuat soal latihan dan mengatur sistem penilaiannya secara online, mengatur jadwal untuk semester, mengatur user, dan melatih sebagai admin. Hasil kuisioner dalam grafik terlihat pada Gambar 3.

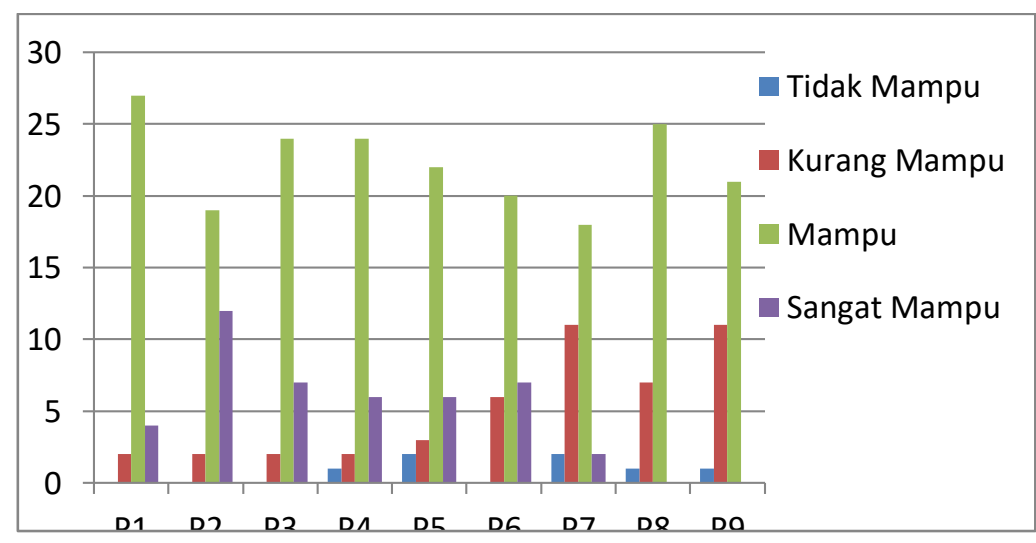

Gambar 3. Grafik hasil evaluasi akhir.

\section{Kuisioner Penilaian Mitra Penyelenggara Hibah Program Pengabdian Kepada Masyarakat (PPM)}

Selain kuisioner yang diberikan pada saat pelaksanaan kegiatan, program pengabdian masyarakat ini juga melakukan penilaian mitra terhadap penyelenggaraan hibah program pengabdian masyarakat. Penilaian ini dilakukan dengan mengajukan 10 pertanyaan seperti pada Tabel 5. 
Tabel 5. Daftar Pertanyaan Penilaian Mitra

\begin{tabular}{|l|l|l|l|l|l|}
\hline No & \multicolumn{1}{|c|}{ PERNYATAAN } & \multicolumn{3}{|c|}{ SKOR } \\
\hline 1. & $\begin{array}{l}\text { Aplikasi/Pelaksanaan PPM UAD telah mampu memberdayakan masyarakat } \\
\text { sehingga masyarakat sanggup berkarya secara mandiri }\end{array}$ & 1 & 2 & 3 & 4 \\
\hline 2. & Program PPM UAD dilakukan sesuai dengan kebutuhan masyarakat & 1 & 2 & 3 & 4 \\
\hline 3. & $\begin{array}{l}\text { Program PPM UAD telah memberikan bekal kepada masyarakat berupa } \\
\text { keterampilan berfikir atau pun keterampilan lainnya. }\end{array}$ & 1 & 2 & 3 & 4 \\
\hline 4. & $\begin{array}{l}\text { Aplikasi/pelaksanaan PPm UAD dalam upaya pembelajaran masyarakat telah } \\
\text { mampu meningkatkan daya nalar masyarakat }\end{array}$ & 1 & 2 & 3 & 4 \\
\hline 5. & $\begin{array}{l}\text { Masyarakat telah memperoleh manfaat /terbantukan dalam penyelesaian } \\
\text { masalahnya dari pelaksanaan PPM UAD }\end{array}$ & 1 & 2 & 3 & 4 \\
\hline 6. & $\begin{array}{l}\text { Pengusung hibab PPM UAD telah melaksanakan sosialisasi kepada } \\
\text { masyarakat atas program yang akan di aplikasikan kepada masyarakat }\end{array}$ & 1 & 2 & 3 & 4 \\
\hline 7. & $\begin{array}{l}\text { Aplikasi/Pelaksanaan PPM UAD telah di laksanakan sesuai dengan rencana } \\
\text { yang telah di buat oleh pengusung hibah }\end{array}$ & 1 & 2 & 3 & 4 \\
\hline 8. & $\begin{array}{l}\text { Pengusung Hibah PPM UAD sangat kompak dalam melaksanakan program- } \\
\text { programnya sesuai dengan keilmuan masing-masing }\end{array}$ & 1 & 2 & 3 & 4 \\
\hline 9. & $\begin{array}{l}\text { LPM UAD telah melaksanakan monitoring terhadap program PPM ke lokasi } \\
\text { Mitra }\end{array}$ & 1 & 2 & 3 & 4 \\
\hline 10. & Program PPM UAD dilaksanakan dengan sarana dan prasarana yang sesuai & 1 & 2 & 3 & 4 \\
\hline
\end{tabular}

Hasil dari kuisioner pada Tabel 5 dapat dilihat pada Tabel 6. Mitra yang melakukan penilaian terdiri dari dua responden yaitu mitra dari SMK Muhammadiyah 1 Moyudan dan SMK Muhammadiyah 2 Moyudan.

Tabel 6. Daftar Pertanyaan Penilaian Mitra

\begin{tabular}{|c|c|c|c|c|c|c|c|c|c|c|}
\hline Penilaian & P1 & P2 & P3 & P4 & P5 & P6 & P7 & P8 & P9 & P10 \\
\hline sangat tidak setuju & 0 & 0 & 0 & 0 & 0 & 0 & 0 & 0 & 0 & 0 \\
\hline tidak setuju & 0 & 0 & 0 & 0 & 0 & 0 & 0 & 0 & 0 & 0 \\
\hline setuju & 2 & 2 & 1 & 2 & 2 & 1 & 2 & 1 & 2 & 1 \\
\hline sangat setuju & 0 & 0 & 1 & 0 & 0 & 1 & 0 & 1 & 0 & 1 \\
\hline
\end{tabular}

Hasil kuisioner menunjukkan dari para responden menyatakan setuju dan sangat setuju terhadap penilaian terhadap pelaksanaan program hibah pengabdian masyarakat ini dan dari terstimoni yang didapat bahwa mitra mengharakan program ini diadakan kelanjutannya. Hasil penilaian dapat dilihat pada Grafik 3.

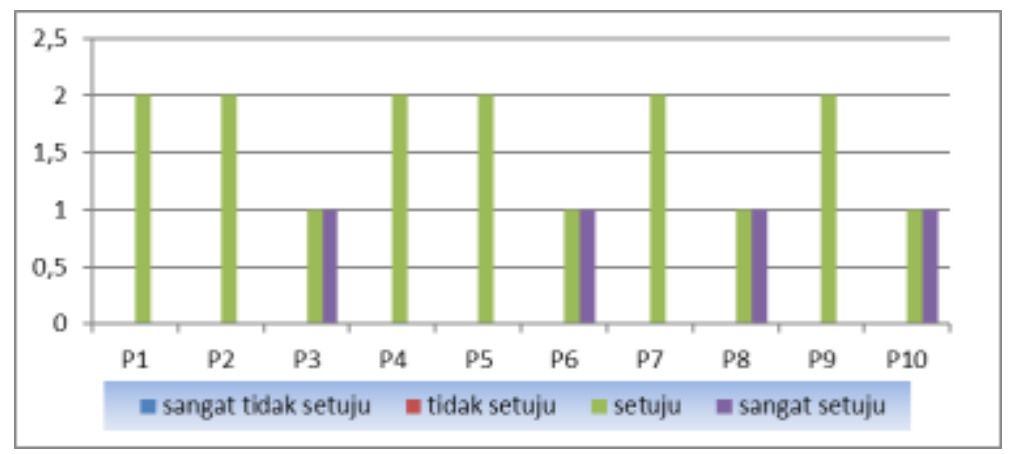

Gambar 3. Grafik hasil evaluasi akhir.

Pelatihan Pengelolaan Materi Pembelajaran Dengan E-Learning Bagi (Sri Winiarti) | 218 


\section{SIMPULAN}

Berdasarkan hasil pelaksanaan program pengabdian kepada masyarakat dapat disimpulkan bahwa:

a. Para guru telah dapat menggunakan, memanipulasi data baik materi maupun soal dengan menggunakan google classroom sesuai dengan mata pelajaran yang diampu disekolah.

b. Para guru dapat membuat kelas yang berisi siswa-siswa yang mengambil mata pelajaran yang mereka ampu.

Para guru dapat menggunakan moodle sebagai dasar pembelajaran e-learning.

\section{DAFTAR PUSTAKA}

Kuswari, H. (2011). E-Learning Adaptif Berbasis Karakteristik Peserta Didik. Prosiding Seminar Nasional Penelitian, Pendidikan dan Penerapan MIPA, Fakultas MIPA, Universitas Negeri Yogyakarta.

Google.com. (2018). About Classroom. Diakses pada 16 April 2018. https://support.google.com/edu/classroom/answer/6020279?hl=en

Moodle.org. (2018). About Moodle. Diaksses pada 16 April 2018. https://docs.moodle.org/34/en/About_Moodle

\section{UCAPAN TERIMAKASIH}

Program Pengabdian kepada Masyarakat (PPM) ini didukung oleh Lembaga Pengabdian kepada Masyarakat dalam skema PPM Reguler dengan Nomor Kontrak No: L2/SPK-PPM-33/LPTT-UAD/I/2018 Tanggal 4 Januari 2018. 
